\title{
A Decision Support Tool for the Management of Multi-reservoir Systems
}

\author{
D. Koutsoyiannis ${ }^{1}$, A. Efstratiadis ${ }^{1}$, and G. Karavokiros ${ }^{1}$ \\ ${ }^{1}$ Department of Water Resources, Faculty of Civil Engineering, National Technical University, Athens
}

Contact: Demetris Koutsoyiannis, Department of Water Resources, Faculty of Civil Engineering, National Technical University, Heroon Polytechniou 5, GR-157 80 Zografou, Greece; e-mail dk@hydro.ntua.gr; URL: http://www.hydro.ntua.gr/faculty/dk

Keywords: water resources management, hydrosystems, operation rules, parameterization-simulationoptimization methodology

\begin{abstract}
A decision support tool is developed for the management of water resources, focusing on multipurpose reservoir systems. This software tool has been designed in such a way that it can be suitable to hydrosystems with multiple and very often contradictory water uses and operating goals, calculating complex multi-reservoir systems as a whole. The mathematical framework is based on the original scheme parameterization-simulation-optimization. The main idea consists of a parametric formulation of the operating rules for reservoirs and other projects (i.e. hydropower plants). This methodology enables the decrease of the decision variables, making feasible the location of the optimal management policy, which maximizes the system yield and the overall operational benefit and minimizes the risk for the management decisions. The program was developed using advanced software engineering techniques. As proved two detailed case studies, it is flexible enough and thus suitable for use to a wide range of applications, so it can be helpful to water and power supply companies and related authorities.
\end{abstract}

\section{Introduction}

The design and operation of surface water systems are the most typical watershed management problems. The fundamental components that make up surface water systems include reservoirs and their withdrawal structures and spillways as well as pipelines, irrigation channels and hydropower units. They also include the watershed as a source of water as well as the physical aquatic environment and the associated ecosystems.

Water resources management requires system-wide decision-making and control that considers an integrated viewpoint (Grigg, 1996). It is a scientific area rich in problems and challenges. The large number of variables involved, the stochastic nature of future inflows, the nonlinearity of dynamics and other uncertainties of water resources systems render their management a difficult but imperative task. Complexity further increases when desiring to combine multiple benefits arising from reservoir system operation (e.g., hydropower, irrigation, etc.), frequently competitive or even conflicting, together with the reduction of natural risks (e.g., flood control) and the environmental requirements. Many times, the management of large hydrosystems, especially when they lie on more than one watershed, raises conflicts between authorities or organizations with different interests (e.g., water supply companies, farmers leagues, ecologists).

The problem of planning and managing multipurpose reservoir systems, most often stated as an optimal control problem, has been and continues to be the subject of extensive research work. Several methods have been proposed during the past decades, offering a wide range of choices and solutions. We can easily group all existing methods in two large categories: system analysis techniques (Mays and Tung, 1996), better known as optimization methods, and simulation models. 
Due to the stochastic aspect of water resources systems, deterministic optimization methods, such as linear and dynamic programming (Loucks et al., 1981; ReVelle, 1999), cannot provide optimal solutions or, more accurately, cannot estimate the reliability of the proposed solutions. On the other hand, stochastic dynamic programming, which has been repeatedly used by many researchers (e.g., Su and Deininger, 1972, 1974; Askew, 1974a, b; Sniedovich, 1979; 1980a, b; Bras et al., 1983; Stedinger et al., 1984), is subject to the "curse of dimensionality", requiring excessive amounts of computer time and storage. To increase the efficiency of the solution algorithm, some researchers have treated the inflow uncertainty in an analytic way without state-space discretization (Wasimi and Kitanidis, 1983; Georgakakos and Marks, 1987). The latter represented the reservoir system dynamics in a state-space form and proposed an extension of stochastic control theory, which they termed extended linear quadratic Gaussian (ELQG). In this way hey obtained a very efficient algorithm at the expense of accurate representation of the stochastic structure of inflows, which was tackled in later studies (Georgakakos, 1989; Georgakakos et al., 1997; Georgakakos et al., 1998).

In spite of the large number of optimization methods available in the literature, simulation techniques remain the primary tool for reservoir planning and management studies in practice. Simulation allows a more detailed and faithful representation of a realworld system's performance than optimization models do (Loucks and Sigvaldason, 1982). Moreover, they can be easily combined with synthetically generated inflow sequences (Loucks et al., 1981). The main drawback of simulation is that it requires prior specification of the system operating policy. In consequence, the only way to locate an optimal policy is through subsequent trials. Many researchers have employed optimization methods within simulation models (Evenson and Moseley, 1970; Sigvaldason, 1976; Ginn and Houck, 1989; Johnson et al., 1991; Tejada-Guibert et al., 1993). These techniques do not result in optimal solution but rather facilitate compliance with the predefined operating rules (Oliveira and Loucks, 1997).

Such rules are often heuristic and define desired storage and release targets in terms of some state variables. Among them are the well-known space rule (Bower et al., 1962) and the relative New York Rule (NYC) (Clark 1950, 1956), both applied in water supply systems, whose aim is to reduce loses due to spills. Heuristic rules are applicable only on ideal systems with no constraints relative to storage capacities or water withdrawals. In reatworld applications they are accompanied by special algorithms that regulate storage and release targets so as to be consistent with physical and operating constraints (Stedinger et al., 1983; Loucks and Sigvaldason, 1982; Yeh, 1985; Johnson et al., 1991).

Recently, Nalbantis and Koutsoyiannis (1997) proposed a framework that combines simulation and optimization in quite a different scheme. Their methodology does not use the step-by-step releases of the reservoirs as control variables thus avoiding an extremely large number of variables. Instead, it introduces simple parametric rules describing their operation policy using a few parameters. The unknown parameters are estimated by nonlinear optimization, employing stochastic simulation to evaluate the objective function value for each trial set of parameter values. In that manner, the physical constraints of the system are handled by the simulation procedure and the control variables of the problem, namely the parameters, do not depend on inflow series but rather on their statistical properties. A decision support tool, which implements the methodology mentioned above, has been developed and applied to two of the most complex hydrosystems in Greece, particularly diverse in terms of their structure and purposes. The program can be adapted in a plethora of hydrosystems with a variety of goals and constraints, such as consumptive (e.g., irrigation, water supply) and non-consumptive uses (e.g., hydropower, reservoir storage control, minimum flow preservation).

This paper is organized in five sections. First, the basics of the proposed mathematical framework are presented. Next the parameterization-simulation-optimization methodology is explained. Some information concerning the software tool and its capabilities is included in the following section. After, 
two applications to reatworld reservoir systems are examined to assess the reliability and efficiency of the proposed methodology. The last section summarizes the conclusions and discusses future prospects.

\section{Mathematical Framework}

A system of $N$ reservoirs, each having a storage capacity $K_{i}$, is assumed for which an operating policy is sought. The policy is focused on various water uses such as consumptive uses, hydropower generation, environmental preservation or storage control (for flood prevention). The reservoirs are connected in series or in parallel, forming a network with any topology. Water is withdrawn from some or all of them in order to meet either downstream target water demand or power generation targets.

System dynamics at any instant $t$ are described by a set of mass conservation (water balance) equations:

$$
S_{i}(t+1)=S_{i}(t)+I_{i}(t)-L_{i}(t)-R_{i}(t)
$$

where $S_{i}(t)$ is the storage for reservoir $i ; I_{i}(t)$ is the inflow rate from the upstream system, including the catchment runoff; $L_{i}(t)$ includes various losses due to evaporation, rainfall, seepage and spillway operation; and $R_{i}(t)$ is the controlled release rate.

Since the release $R_{i}(t)$ of each reservoir is unknown, the system has a large number of degrees of freedom, more precisely $N \times T$, where $T$ is the total number of simulated time steps (e.g., years or months). To reduce this number, the idea of parameterization is introduced.

Let $V$ denote the total active storage (excluding dead volume) in the system at the end of a time period of interest and $S_{i}$ be the respective active storage for reservoir $i$. Reference to the time interval is omitted for convenience. Apparently,

$$
\sum_{i=1}^{N} S_{i}=V
$$

The actual problem is to determine the releases from all reservoirs so that their sum equals the total water demand. Equivalently, the problem is to distribute $V$ into the $N$ reservoirs such that the later is satisfied. This can be done in numerous ways, as the problem has several degrees of freedom. A specific way to perform this distribution is termed an operating rule. Nalbantis and Koutsoyiannis (1997) introduced a parametric linear rule, whose a slightly modified form is

$$
S_{i}^{*}=K_{i}-a_{i} K+b_{i} V
$$

where $K$ is the total capacity of the system, $a_{i}$ and $b_{i}, i \in\{1, \ldots, N\}$ are unknown parameters and $S_{i}{ }^{*}$ stands for the target storage for the reservoir $i$ at the end of the period, which generally differs from the real storage $S_{i}$ due to the physical constraints that were not considered in this stage. After extensive analysis, Nalbantis and Koutsoyiannis (1997) concluded that the operating rule in the linear form of (3) is a convenient and efficient parameterization of the problem. Moreover, they found that the parameterization is still efficient even if we omit parameters $a_{i}$ (set them to zero). Generally, the parameters can be considered constant in time or, alternatively, they may be different for the refill (wet) and the drawdown (dry) season.

Subsequently, because in (3) the physical constraints that demand that the storage cannot be negative nor can it exceed the capacity $K_{i}$ are ignored, they modified (3) using a simple adjusting procedure so that

$$
S_{i}{ }^{*}= \begin{cases}0 & K_{i}-a_{i} K+b_{i} V<0 \\ K_{i}-a_{i} K+b_{i} V & 0 \leq K_{i}-a_{i} K+b_{i} V \leq K_{i} \\ K_{i} & K_{i}-a_{i} K+b_{i} V>K_{i}\end{cases}
$$

The final operating rule is completely determined from the initial parameters $a_{i}$ and $b_{i}$, irrespectively of all corrections. Therefore the total number of control variables of the system reduces to $2 N$ and becomes 
independent of the number of simulated time steps, $T$. In Figure 1 the parametric operational rules for three hypothetical reservoirs are plotted; solid lines represent the initial linear rules (equation 3) whereas bold lines represent the adjusted ones.

Only the fundamental principles of the methodology have been mentioned here. For more details, including justification of the parametric rule's form, the reader may refer to Nalbantis and Koutsoyiannis (1997).

In addition to the parameters of the operating rule other control variables may be introduced depending on the specific problem examined each time. Such variables could be the target withdrawal of the system or the target energy production from the system, etc. In any case the number of control variables in this formulation remains very limited and obviously the problem is particularly nonlinear.

\section{The Parameterization-simulation-optimization Scheme}

A flowchart representation of the parameterization-simulation-optimization scheme is given in Figure 2 . Input data are a) the hydrosystem structure, namely the system components and their attributes, and the topology; b) the hydrologic data series, either taken from historical records or generated synthetically. The system is parameterized using the parametric operation rule described above. Parameters of the operating rule and, on occasion, a target withdrawal or target power production are considered as control variables of the problem to be determined by optimization. The objectives of the management are expressed mathematically as the performance index of the system. The operational constraints of the system are incorporated into the performance index as penalty terms.

Assuming that parameters $a_{i}$ and $b_{i}$ are known, the target releases from each reservoir will be also known at each time step. Due to the physical constraints of the hydrosystem (e.g., discharge capacity of pipes, channels and penstokes), the actual releases may differ from the desired ones and their estimation is done via simulation. Within simulation, an internal optimization procedure may be necessary. That case arises when flows in the network can be conducted via multiple paths. A transshipment problem is formulated and the hydrosystem's layout is represented in a digraph form [Figure 3]. Three nodes, a "source" node, a "sink" node and a "storage" node represent each reservoir. Each link (pipe or channel) corresponds to an edge for which a unit transportation "cost" is introduced, expressing either the real water transportation price or a penalty value, depended on the deviation of the actual flow from the desired one.

Because parameters are not known, but rather are to be optimized, simulation is driven by an external optimization procedure. The method is applied in the form of successive steps or iterations. Trial values are assigned to the parameters and the performance index (objective function) of the system is evaluated, by performing a simulation of the system operation for the whole operation period. New parameter values are chosen according to an iterative nonlinear optimization method (see below) and the algorithm proceeds in this way for a number of iterations until convergence to an optimal solution.

The results of the model are the values of parameters and other control variable that maximize the performance index of the system and the corresponding optimal value of the index.

Attempting a comparison between the proposed, low-dimensional methodology and a conventional, nonparametric optimization we can distinguish four advantages of the former:

1. Due to parameterization, the number of control variables is small, reducing the computational effort of optimization. 
2. Parametric optimization can be combined with simulation procedures whereas conventional optimization methods cannot and, thus, in the latter case all physical constraints of the system must be entered as mathematical constraints in the optimization procedure.

3. In conventional methods, the optimal solution depends on inflow series, whereas in the parametric methodology the optimum depends only on their statistical properties. Within stochastic simulation, the reliability of the management policy can be estimated.

4. Optimization models need continuous runs with updated hydrological data, whereas a hydrosystem optimized via the parametric rule based procedure can be operated without running the model again.

A disadvantage of the method is that the form of the operation rules is predefined; notwithstanding several trials proved that the differences between the linear rule given by (3) and other mathematical expressions (e.g., quadratic) are not significant (Nalbantis and Koutsoyiannis, 1997).

\section{Program Description}

The parameterization-simulation-optimization scheme described above has been implemented in Hydronomeas (a Greek term meaning the "distributor of water"), a software application for planning and management of multi-reservoir multipurpose hydrosystems. The source code is in Object Pascal programming language, designed for Windows environment [Figure 4]. A first version of the program was developed for academic purposes (Karavokiros et al., 1999; Efstratiadis and Zervos, 1999) and its improved, operational version is in progress (Karavokiros and Efstratiadis, 2000).

The decision support system gives answers to several questions, about

- The maximum annual total withdrawal (or firm energy) from the hydrosystem, for a given hydrologic regime and a given reliability.

- The minimum failure probability for a given set of operational goals and a given hydrologic regime.

- The minimum cost for a given set of operational goals, a given hydrologic regime and a given reliability.

- The optimal management policy that assures the above objectives.

- The consequences of modifications in the hydrosystem (e.g., construction of new projects), and the impacts of different management policies or hydroclimatic scenarios.

A brief representation of the software system structure and relations between its modules is given in Figure 5. Hydronomeas is supported by a database where all information concerning the hydrosystem is stored. Database architecture is based on the entity-relationship (E/R) model, described by Sommerville (1998). The components of the real system are replaced by five entities, namely nodes, aqueducts, energy conversion units, hydrologic time series and (operational) targets [Figure 6]. More specifically:

A node can be a source (e.g., reservoir, aquifer) or sink (e.g. consumption area) of water or simply an intermediate point (junction) of the network. A node is assigned some attributes. For example, the attributes of a reservoir are the river basin area, the dead volume, the storage capacity, the storageelevation-area function, the seepage equation, the inflow series file etc.

1. An aqueduct refers to a natural or artificial channel connecting two nodes and the flow direction is defined from the corresponding hydraulic heads. Some of the attributes of an aqueduct are the discharge capacity, the head-discharge relationship, the leakage function, the unit transportation price, etc. Special restrictions can be imposed on aqueduct, permitting their use only for specific reasons, i.e. reservoir evacuation, and limiting their time-use availability (e.g., to provide for maintenance and repairing works). Natural channels (e.g., rivers) do not have capacity or timeusage limits. 
2. An energy conversion unit is either a turbine station or a pumping station or a pumped storage station, referred to a unique aqueduct. Pumping facilities may permit bi-directional flow through aqueducts. The fundamental attributes of an energy conversion unit are the power capacity and the discharge-power relationship.

3. Time series are referred to reservoirs and contain runoff, rainfall and evaporation data for the simulated period, all expressed as equivalent depths. Hydrologic data can either be obtained from historical records or generated. For this purpose, a two-level (annual and monthly) multivariate stochastic model is linked to Hydronomeas. The generation of annual series is performed via a generalized long-memory scheme (Koutsoyiannis, 2000), whereas monthly series are generated by disaggregation (Koutsoyiannis and Manetas, 1996, Koutsoyiannis, 1999).

4. A target is an operational goal or system constraint, referred to a unique component of the network. Multipurpose hydrosystems need to serve (by definition) a large number of water uses that are usually unrelated or even competitive. Hydronomeas supports a variety of such uses that can be classified in four major categories a) water consumption, b) minimum flow preservation either in aqueducts or in natural channels to satisfy environmental requirements, c) power generation in hydroelectric plants and d) reservoir storage control, either to ensure the existence of a minimum safety storage or to prevent overrun of a maximum storage value that guarantees flood-control capabilities. Note that power targets are referred to firm energy production, namely the amount of hydroelectric peak energy that is available on an assured basis (Grigg, 1996). All target values are given in monthly steps. The program also handles long-term trends, corresponding to predicted demand changes. A maximum allowable failure probability is assigned to each target, usually depending on target type and on an assessment of the impacts in case of failure.

Network structure and individual component attributes can be retrieved or modified via the network management module, which is the interface between the database and the program. After the desired changes have been completed all database information is loaded via the control module, thus rendering it completely independent. A number of other general options must be specified before setting off the optimization procedure, such as the objective function, input arguments of the optimization algorithm, economical aspects, etc.

The optimization module assigns values to parameters, evaluates the objective function by performing a simulation of the system's operation for the complete simulation period and then modifies parameters appropriately. In any stage, the evolution of a simulation can be viewed via the dynamic visualization module. The process is repeated until the convergence criterion for defining an optimal solution is met. The analytical results, presented in tabular or chart form, include, apart from the optimal operation rules chart, average hydrologic, energy and economic balances, the failure probability for each target or constraint of the system, etc.

As described before, simulation model requires an internal step-by-step optimization procedure, which is implemented via the network simplex algorithm (Smith, 1982). For the external (global) optimization process two alternative approaches have been implemented.

The first approach uses enumeration: a uniform division of the feasible area is implemented and all possible combinations of parameter values (all the grid points of the parameter space) are evaluated (Loucks et al, 1981). The process is applied in the form of successive steps, with grids that are nested to each other and become progressively finer. This method is extremely time-consuming, and the number of calculations required increases exponentially with the number of parameters. On the other hand, it is very likely that the global optimal solution will be tracked down, although there is no absolute guarantee. 
The second approach incorporates efficient nonlinear optimization methods, which reduce optimization time, especially for large systems and long simulation periods. Such methods start from a random set of parameters and pursue a search towards the optimum. Moreover, to increase the chance of locating the global optimal solution rather than ending with local optima, multiple searches are conducted starting from different initial values, which are randomly determined. Two well-known algorithms, the multi-start downhill simplex method (Press et al., 1992) and the shuffled complex evolution method (Duan et al., 1992) are incorporated at the current version of the program. An interesting feature of the following version will be the use of high performance computing (parallel processing) technology, in order to take advantage of the power of computer clusters to accelerate the optimization process.

\section{Applications}

Hydronomeas was used in two major hydrosystems of Greece, the Acheloos-Thessalia reservoir system (western Greece) and the Greater Athens Water Supply reservoir system (central-eastern Greece). These hydrosystems serve the eastern, almost semiarid areas of Greece, where the most people and activities are concentrated, by transporting large amounts of water from the western, rich in aquatic resources, watersheds. The hydrosystems have significant differences concerning general design conception and project characteristics as well as overall management policy, operational constraints and long-term objective goals.

The Acheloos-Thessalia reservoir system will be, when completed, the largest hydrosystem in Greece. Acheloos River is one of the most important of the country, having a mean annual discharge of almost $150 \mathrm{~m}^{3} / \mathrm{s}$. Three power stations (Kremasta, Kastraki and Stratos) are installed along the river, producing a significant part of the hydroelectric energy of Greece. Downstream of the dams, the Aitoloakarnania plain is irrigated and moreover, sensitive estuary and aquatic ecosystems are maintained from the river flow. On the other hand, Thessalia plain, which is located in central Greece, stands as a key agricultural region for the national economy. However, in recent years, the impacts of agricultural expansion have resulted in extensive water shortages and ecosystem degradation. To reverse this trend and to maintain the sustainability of the land resources, a water diversion of $600 \mathrm{hm}^{3} / \mathrm{yr}$ has been proposed from the nearby Acheloos river basin. The diversion project and the future operational policy of the entire hydrosystem continues to provoke great conflicts between politicians, engineers, Aitoloakarnania and Thessalia farmer leagues, ecologists and the Public Power Corporation (for more details, the reader may refer to the relative web pages: www-penelope.drec.unilim.fr/penelope/cases/greek/GRCase.htm and www.agrinio.net/perivallon/enaxel11.html). It is obvious that an integrated, multidisciplinary approach is required, to handle all the technical, social, economic and environmental aspects of the management.

Upon completion, the hydrosystem will consist of 7 reservoirs and 7 hydroelectric power plants [Figure 7]. Two of them are currently under construction in the Upper Acheloos watershed (Mesohora and Sykia), while the remaining projects (the river diversion tunnel and the related reservoirs in Thessalia, Pyli and Mouzaki) are still under study. Specific features of reservoirs and power plants are given in Table 1. Downstream of Mouzaki, at Mavromati, the construction of a small regulating dam is also planned. Reservoir leakages are $6 \mathrm{~m}^{3} / \mathrm{s}$ in Kremasta and $4 \mathrm{~m}^{3} / \mathrm{s}$ in Stratos, while at other reservoirs are either negligible or unavailable.

All projects except Pyli have hydropower generation units, the number and capacities of which are shown in Table 2. All hydroelectric power plants are considered as peak energy facilities. Daily peak period is assumed to last 6 hours. Some studies examined the installation of pumped storage hydropower plants in Pefkofyto and Mouzaki, in order to increase peak power generation. In that case, pumping is limited to maximum 8 hours per day, so as to function exclusively with night energy. Pumping capabilities are also assumed to operate during the wet season (September to March), when no water transfer towards 
Thessalia takes place. On the contrary, during the dry season pumps are activated only if normal flow is not adequate to fulfill power generation targets.

Except for energy generation and flood control, the reservoir system is expected to provide water for irrigation and maintain sufficient in-stream flows to preserve environmental quality. Consumptive water uses are located at the edges of the system, downstream of Stratos and Mavromati, which constitute the main irrigation dams for the Aitoloakarnania and the Thessalia plain respectively. Irrigation demand in Aitoloakarnania rises to $450 \mathrm{hm}^{3} / \mathrm{yr}$, whereas in Thessalia the irrigation requirement is set to $600 \mathrm{hm}^{3} / \mathrm{yr}$. Moreover, according to the environmental impacts assessment study of the Acheloos Diversion Project, a minimum river flow is set to $1.5 \mathrm{~m}^{3} / \mathrm{s}$ downstream Mesohora, $5 \mathrm{~m}^{3} / \mathrm{s}$ downstream Sykia and $21 \mathrm{~m}^{3} / \mathrm{s}$ at the estuary. Environmental preservation flow is also assumed downstream of Pyli and Mouzaki dams.

Five operational scenarios were studied, regarding either the whole reservoir system or some of its parts (Efstratiadis and Zervos, 1999) in order to test Hydronomeas' efficiency for various hydrosystem formations. Scenario 1 comprised only the existing dams in the Lower Acheloos basin, whereas in Scenario 2 the Upper Acheloos reservoirs were added too. Two sub-cases were examined, in order to assess the impacts of diversion onto the Acheloos basin hydropower potential. In case 2a only irrigation demands downstream of Stratos were considered, whereas in case $2 b$ an additional annual withdrawal of $600 \mathrm{hm}^{3}$ from Sykia reservoir was imposed. Scenario 3 deal with the Upper Acheloos watershed, the diversion tunnel and the related projects in Thessalia. Scenario 4 was a study of the entire hydrosystem.

The objective in all scenarios was the maximization of total firm energy production, allowing a $20 \%$ failure probability for all irrigation targets and only $1 \%$ for environmental requirements. Firm energy was defined as power available during $99 \%$ of the whole simulation period, upon the condition that it can be generated within the daily 6-hour peak period. The additional energy generated was considered as secondary energy. All simulations were based on a monthly, 34-year-long (1960-1994) historical data record of runoff, rainfall and evaporation. Some of the results are presented in Table 3. All irrigation and environmental requirements were satisfied with almost zero probability of failure. Results obtained are in general agreement with those of former studies (Georgakakos et al., 1998).

The Greater Athens Water Supply reservoir system supplies water mainly for domestic and industrial use to the metropolitan area of Athens. A schematic layout of the hydrosystem, along with some technical characteristics, is sketched in Figure 8. The system uses surface as well as underground water resources, although the latter are considered only as auxiliary. Two reservoirs, the Mornos reservoir and the natural lake Yliki, are the main storage projects of the system. A small reservoir near Athens, the Marathon reservoir, is also part of the system and it is considered full all the time for emergency situations. The growing water demand and the system's vulnerability to drought during the severe drought of 1988-1993, led public authorities to construct a new dam on the Evinos River, just west of the Mornos watershed, which will be completed until the summer of 2001. Inflows to the Evinos reservoir are of a magnitude comparable to that of inflows to the Mornos reservoir, although the reservoir's storage capacity is quite small in comparison. Water from the Evinos reservoir is diverted through a tunnel to the neighboring Mornos reservoir, which stands as the main storage project for the Evinos River flow as well. Specific attributes of reservoirs are shown in Table 4. Major transfer works of the system are the

Mornos aqueduct, some $200 \mathrm{~km}$ long, which carries water from the homonymous reservoir to Athens via gravity and the Yliki aqueduct, which carries water from Yliki Lake to Marathon reservoir via pumping.

An important feature of the system is that the lake Yliki lies on a karstic geologic formation that causes significant leakage. This depends strongly on the water surface elevation of the lake and may equal half of the annual inflow for high elevations. Analysis of historical data established two distinct leakage- 
elevation relationships, one for the dry period and one for the wet period. Mornos reservoir leakage is concentrated in a limited area of the reservoir and is rather small compared to that of the lake Yliki.

The system's main objective is to provide water to the Greater Athens area, which is divided in four subareas (Kiourka, Menidi, Galatsi, Mandra), allocated downstream of the respective water treatment plants. Secondary objectives are a) the maintenance of minimum safety storage of $35 \mathrm{hm}^{3}$ in Marathon reservoir, b) an environmental peservation flow of $1.0 \mathrm{~m}^{3} / \mathrm{s}$ in the Evinos River, and c) a withdrawal from Yliki Lake for irrigation of the Kopais plain. The latter water use is set to $35 \mathrm{hm}^{3} / \mathrm{yr}$, but may be reduced in case of water shortages in the water supply of Athens.

All simulations were based on two synthetic inflow data sets, each one having a length of 2000 years. Both sets have same statistical characteristics with the historical data, but they strongly differ regarding the hydrologic persistence (i.e., the property by which high flows tend to follow high flows and low flows tend to follow low flows), also referred as the "Hurst phenomenon" (e.g., Kottegoda, 1980). The first set, which is more realistic, assumes long persistence, whereas the second one assumes short persistence and therefore it is less severe.

A particular management policy was considered for groundwater resources. Two thresholds were imposed, the upper one to forbid the usage of groundwater if the active storage of the system is more than $40 \%$ of the total active capacity, and the lower one to enforce their usage if the storage is less than $25 \%$ of the capacity. Between these thresholds, the usage of groundwater depends on economic criteria. The conveyance cost was introduced in terms of energy consumption $\left(\mathrm{kWh} / \mathrm{m}^{3}\right)$ and not in monetary terms.

Two operational scenarios were studied (Karavokiros and Efstratiadis, 2000). Scenario 1 aimed at evaluating the theoretical potential of system water resources. The optimization objective was maximizing the system's firm yield for an adopted reliability level equal to $99 \%$ on an annual basis (only in 1 of 100 years the system cannot meet with success the target), a value that provides a high level of security. The discharge capacity of all aqueducts was set to an infinite value, so as to eliminate any restrictions imposed by conveyance capacity limits of aqueducts. On the other hand, scenario 2 aimed at evaluating the real potential of the system and finding the suitable policy which, ensuring a $99 \%$ reliability level, minimizes the total pumping energy.

The results for the two scenarios are summarized in Figure 9. The mean annual supply of the natural system, namely the mean annual runoff, is about $840 \mathrm{hm}^{3}$, without including groundwater resources. Assuming reservoirs' and aquifers' characteristics and the long-persistence data set, the safe yield of the system is $480 \mathrm{hm}^{3}$. The difference is due to reservoir losses, namely evaporation, spills and leakages. The rest of the projects (aqueducts, pumps, water treatment plants) impose further restrictions, reducing the real potential of the system to $410 \mathrm{hm}^{3}$. Note that the current annual water consumption in Athens is about $370 \mathrm{hm}^{3}$ but it is expected that this amount will be significantly increased, due to the expansion plans of the Athens Water Supply and Sewage Company as well as the remarkable increase of water consumption, which at present is as high as $6 \%$ per year. The study showed that this increase must be reduced; otherwise the system will be unable to satisfy demand in a 10-year horizon.

\section{Summary and Conclusions}

The proposed framework is a generalized decision support system for multi-reservoir planning and management. It includes many innovations, both in the hydrosystems theory and the software application. The system employs an original, low-dimensional technique, named parameterizationsimulation-optimization, which reduces dramatically the number of degrees of freedom, by introducing parametric operation rules and using their parameters as control variables. The proposed framework handles the system dynamics and constraints through simulation, also coupling it with typically nonlinear 
optimization for the parameters of the rules. It is able to incorporate various and competitive water uses, on an inter-basin basis. Output of the model is the best operating policy of the hydrosystem, which guarantees a set of targets and constraints, for a given reliability level and a given hydrologic regime.

The modeling framework was tested in two of the most complex hydrosystems of Greece. The AcheloosThessalia reservoir system, which is not yet completed, will be the largest of the country and, without doubt, the most hard to manage. Several groups with completely different interests as well as the local society are in continuous conflict bout the operation of the projects and their impacts on the natural environment. The application of the model demonstrated that via a suitable management policy, various and contradictory objectives could be accomplished, ensuring also the sustainability in the development of the sensitive river and estuary ecosystems. On the other hand, the Greater Athens Water Supply reservoir system is particularly critical, procuring water for almost the $40 \%$ of the population of Greece. The great drought of recent years proved that the system had little resilience to natural hazards. It is sure that due to the construction of new projects, the probability of water lack is strongly limited; although an optimal management policy could increase this reliability and minimize the operating cost.

\section{Acknowledgements}

The first version of Hydronomeas was implemented within the framework of the project Evaluation and Management of the Water Resources of Sterea Hellas, funded by the Greek Ministry of Environment, Regional Planning and Public Works, Directorate of Water Supply and Sewage. The second edition is developed within the framework of the project Modernization of the Supervision and Management of the Water Resources System of Athens, funded by the Athens Water Supply and Sewage Company, Directorate of General Planning and Design. The authors wish to thank the director I. Nazlopoulos, the associate director A. Xanthakis, and the members of the project committee for the support on the research. Thanks are also due to $\mathrm{N}$. Zervos for his collaboration in the development of the first version of the program.

\section{References}

Askew, A.. 1974a. Chance-constrained dynamic programming and the optimization of water resource systems. Water Resources Research 10(6): 1099-1106.

. 1974b. Optimum reservoir operating policies and the imposition of a reliability constraint. Water Resources Research 10(1): 51-56.

Bower, B. T., M. M. Hufschmidt, and W. H. Reedy. 1962. Operating procedures: Their role in the design and implementation of water resource systems by simulation analysis. in Design of Water Resource Systems, edited by A. Maass et al., chap. 11, pp. 443-458, Harvard University Press, Cambridge, Mass.

Bras, R., R. Buchanan, and K. Curry. 1983. Real-time adaptive closed-loop control of reservoirs with the High Aswan Dam as a case study. Water Resources Research 19(1):33-52.

Clark, E. J. 1950. New York control curves. Journal of American Water Works Association 42(9):823827.

1956. Impounding reservoirs. Journal of American Water Works Association 48(4): 349-354.

Duan, Q., S. Sorooshian, and V. Gupta. 1992. Effective and efficient global optimization for conceptual rainfall-runoff models. Water Resources Research 28(4):1015-1031.

Efstratiadis, A., and N. Zervos. 1999. Optimal management of reservoir systems - Application on the Acheloos-Thessalia system. Diploma Thesis, Faculty of Civil Engineering, National Technical University of Athens, Athens (in Greek).

Evenson, D. E., and J. C. Moseley. 1970. Simulation/optimization techniques for multi-basin water resource planning. Water Resources Bulletin 6(5):725-736.

Georgakakos, A. P. 1989. Extended linear quadratic Gaussian control: Further extensions. Water Resources Research 25(2):191-201. 
Georgakakos, A. P., and D. H. Marks. 1987. A new method for the realtime operation of reservoir systems. Water Resources Research 23(7):1376-1390.

Georgakakos, A. P., H. Yao, C. DeMarchi and M. Mullusky. 1998. A decision support system for the Western Sterea Hellas water resources system. Volume 41 in Research Project Evaluation and Management of the Water Resources of Sterea Hellas, Greek Ministry of Environment, Regional Planning and Public Works and National Technical University of Athens, Athens.

Georgakakos, A. P., H. Yao, and Y. Yu. 1997. Control models for hydroelectric energy optimization. Water Resources Research 33(10):2367-2379.

Ginn, T. R., and M. H. Houck. 1989. Calibration of an objective function for the optimization of real time reservoir operations. Water Resources Research 25(4):591-603.

Grigg, N. S., 1996. Water Resources Management. McGraw-Hill, New York.

Johnson, S. A., J. R. Stedinger, and K. Staschus. 1991. Heuristic operating policies for reservoir system simulation. Water Resources Research. 27(5):673-685.

Karavokiros, G., and A. Efstratiadis. 2000. Design of management support system's initial version. Volume 4 in Research Project Modernization of the Supervision and Management of the Water Resources System of Athens, Water Supply and Sewage Corporation of Athens and National Technical University of Athens, Athens (in Greek).

Karavokiros, G., D. Koutsoyiannis, and N. Mandellos. 1999. Model development for simulation and optimization of the Eastern Sterea Hellas hydrosystem. Volume 40 in Research Project Evaluation and Management of the Water Resources of Sterea Hellas, Greek Ministry of Environment, Regional Planning and Public Works and National Technical University of Athens, Athens (in Greek).

Kitanidis, P. K., and E. Foufoula-Georgiou. 1987. Error analysis of conventional discrete and gradient dynamic programming. Water Resources Research 23(5):845-858.

Kottegoda, N. T. 1980. Stochastic Water Resources Technology. Macmillan Press.

Koutsoyiannis, D., and A. Manetas. 1996. Simple disaggregation by accurate adjusting procedures. Water Resources Research 32(7):2105-2117.

Koutsoyiannis, D. 1999. Optimal decomposition of covariance matrices for multivariate stochastic models in hydrology. Water Resources Research 35(4):1219-1229.

. 2000. A generalized mathematical framework for stochastic simulation and forecast of hydrologic time series. Water Resources Research 36(6):1519-1534.

Loucks, D. P., and O. T. Sigvaldason. 1982. Multiple reservoir operation in North America. in The Operation of Multiple Reservoir Systems, edited by Z. Kaczmarck and J. Kindler, IIASA Collab. Proc. Ser., CP-82-53, 1-103.

Loucks, D. P., J. R. Stedinger, and D. A. Haith. 1981. Water Resource Systems Planning and Analysis. Prentice-Hall, Englewood Cliffs, New Jersey.

Mays, L. W., and Y. K. Tung, 1996. Systems analysis. in Water Resources Handbook, McGraw-Hill, New York.

Nalbantis, I., and D. Koutsoyiannis. 1997. A parametric rule for planning and management of multiplereservoir systems. Water Resources Research 33(9):2165-2177.

Oliveira, R., and D. P. Loucks. 1997. Operating rules for multi-reservoir systems. Water Resources Research 33(4):839-852.

Press, W. H., S. A. Teukolsky, W. T. Vetterling, and B. P. Flannery. 1992. Numerical Recipes in C. $2^{\text {nd }}$ edition, Cambridge University Press, Cambridge, U.K.

ReVelle, C. Optimizing Reservoir Resources. 1999. John Wiley \& Sons.

Sigvaldason, O. T. 1976. A simulation model for operating a multipurpose multi-reservoir system. Water Resources Research 12(2):263-278.

Smith, D. K. 1982. Network Optimization Practice: A Computational Guide. John Wiley \& Sons.

Sniedovich, M. 1979. Reliability-constrained reservoir control problems, 1, Methodological issues. Water Resources Research 15(6):1573-1582. . 1980a. A variance-constraint reservoir control problem, Water Resources Research 16(2): 271-274. 
Sniedovich, M. 1980b. Analysis of a chance-constraint reservoir control model. Water Resources Research 16(5):849-853.

Sommerville, I. 1998. Software Engineering. Addison-Wesley Publishers.

Stedinger, J., B. F. Sule, and D. Loucks. 1984. Stochastic dynamic programming models for reservoir operation optimization. Water Resources Research 20(2), 1499-1505.

Stedinger, J., B. F. Sule, and D. Pei. 1983. Multiple reservoir system screening models, Water Resources Research, 19(6):1383-1393.

Su, S., and R. Deininger. 1972. Generalization of White's method of successive approximations to period Markovian decision processes. Operations Research 20(2):318-326.

. 1974. Modeling the regulation of Lake Superior under uncertainty. Water Resources Research 10(1):11-25.

Tejada-Guibert, J. A., S. A. Johnson, and J. R. Stedinger. 1993. Comparison of two approaches for implementing multi-reservoir operating policies derived using stochastic dynamic programming. Water Resources Research 29(12):3969-3980.

Wasimi, S., and P. K. Kitanidis. 1983. Realtime forecasting and daily operation of a multi-reservoir system during floods by linear quadratic Gaussian control. Water Resources Research 19(6):1511-1522.

Yeh, W. W.-G. 1985. Reservoir management and operations models: A state-of-the-art review, Water Resources Research, 21(12):1797-1818.

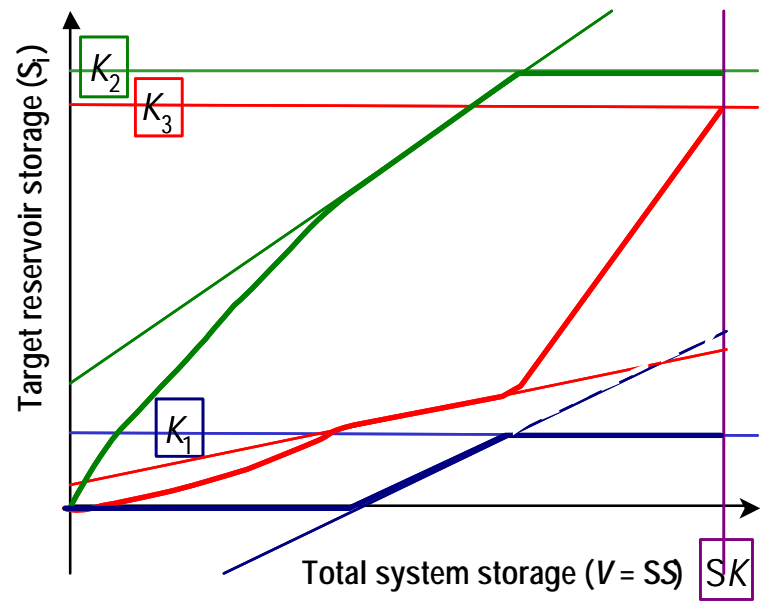

Figure 1 Graphical Representation of Operating Rules for Three Hypothetical Reservoirs.

Note: Solid lines represent the initial linear rules whereas bold lines represent the adjusted ones. 


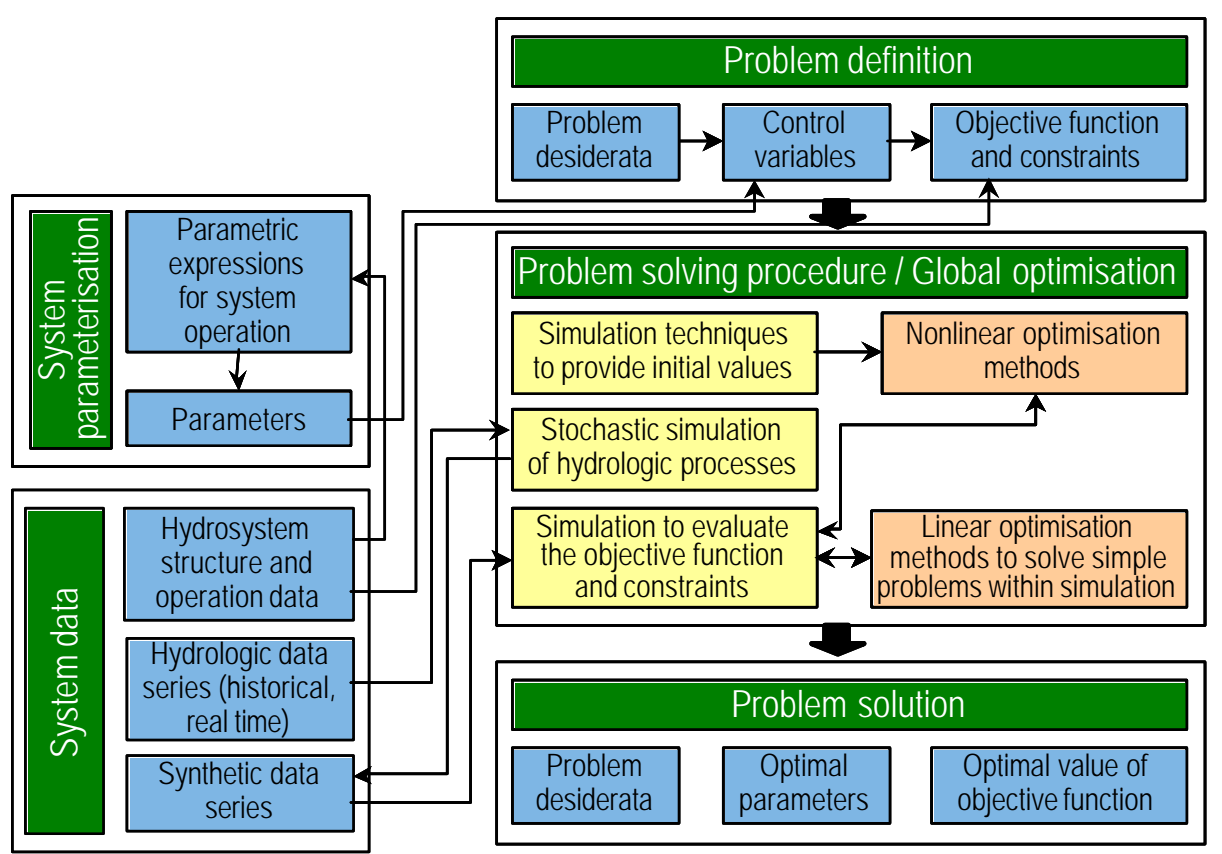

Figure 2 Outline of the Parameterization-Simulation-Optimization Methodology.

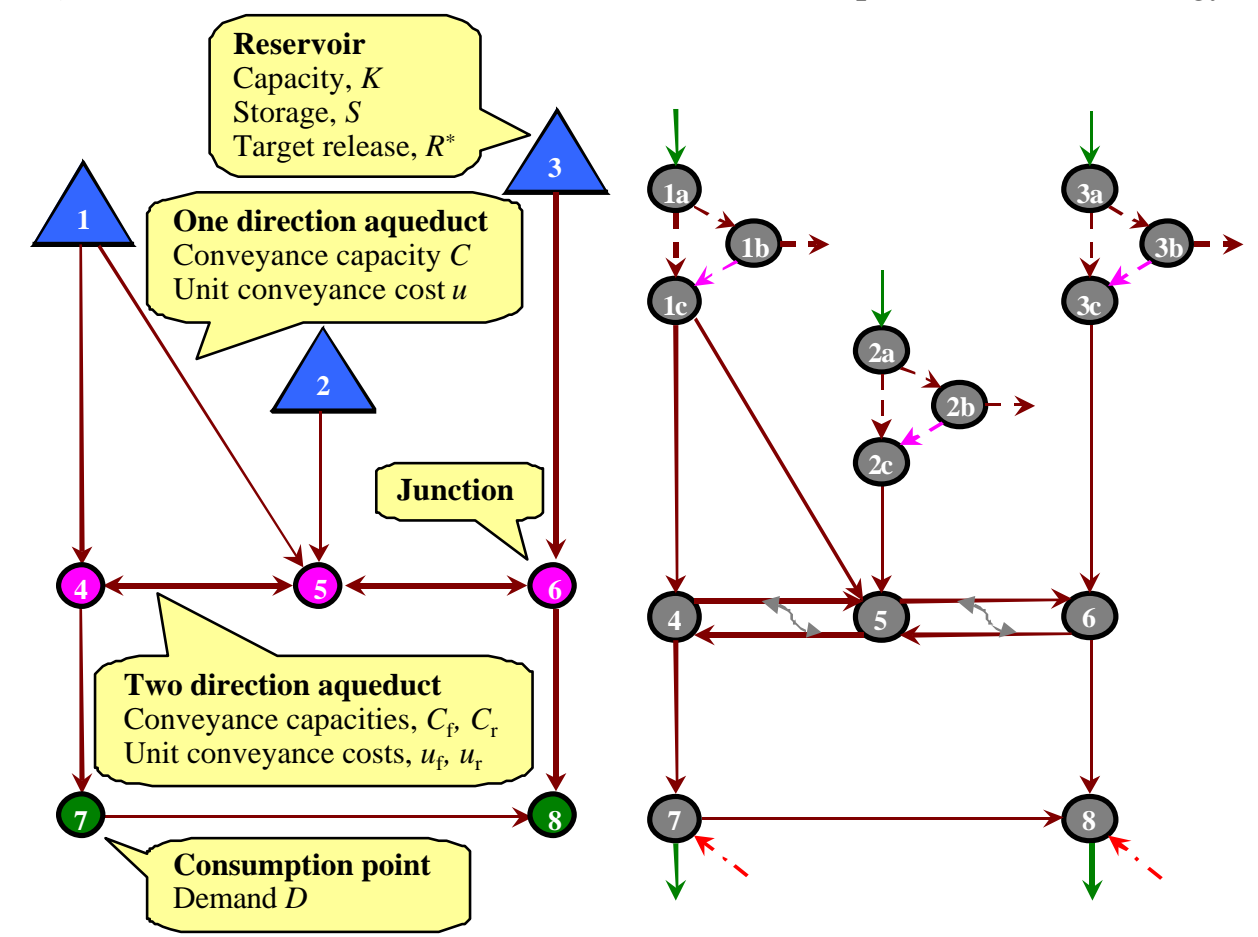

Figure 3 Transformations of Hydrosystem Components to Digraph Components. 


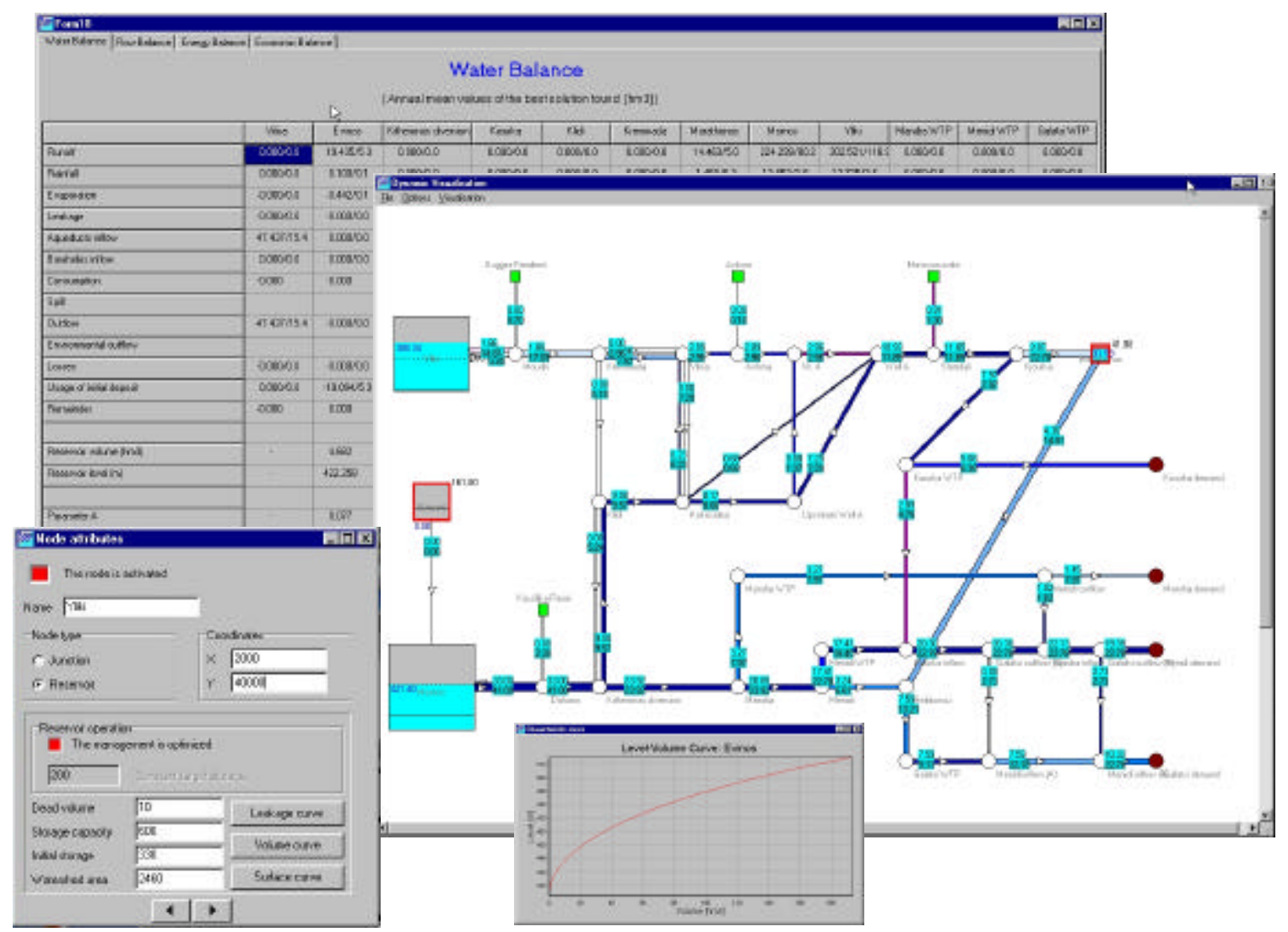

Figure 4 Characteristic Modules of Hydronomeas with Dynamic Visualization Form in the Foreground.

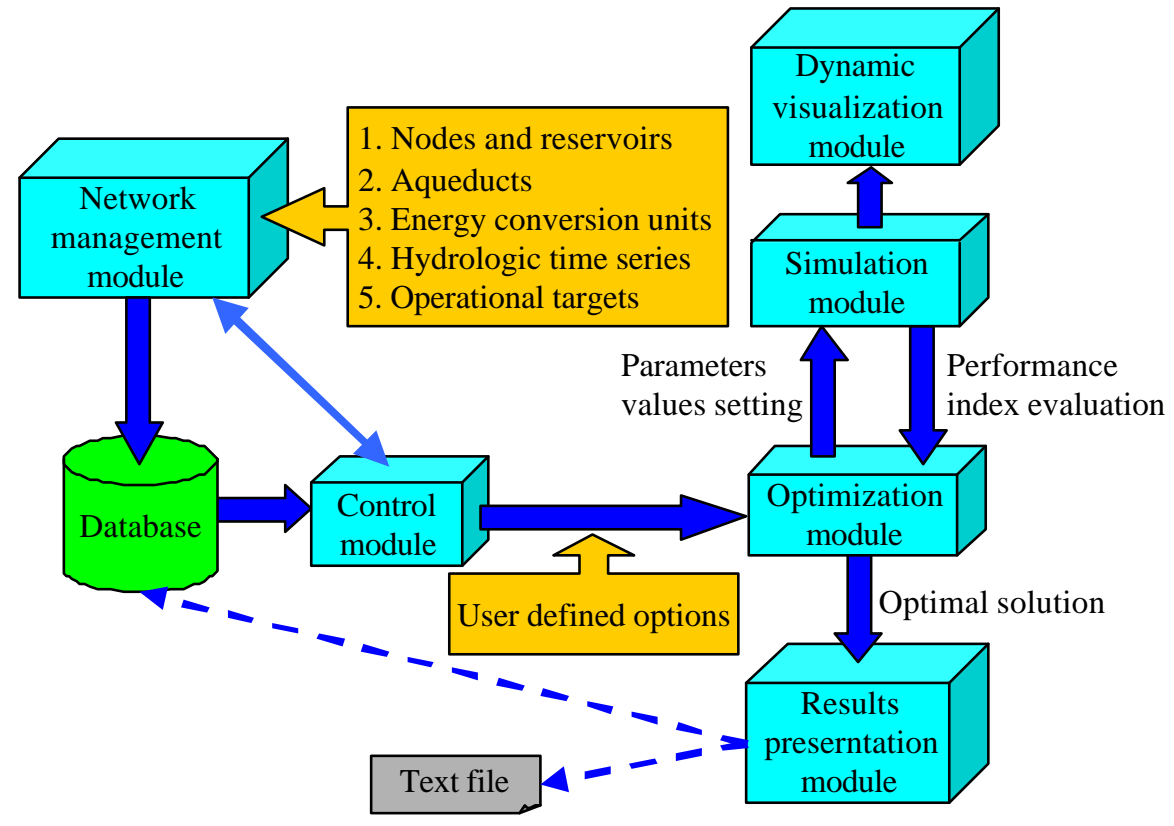

Figure 5 The Decision Support System Modules. 

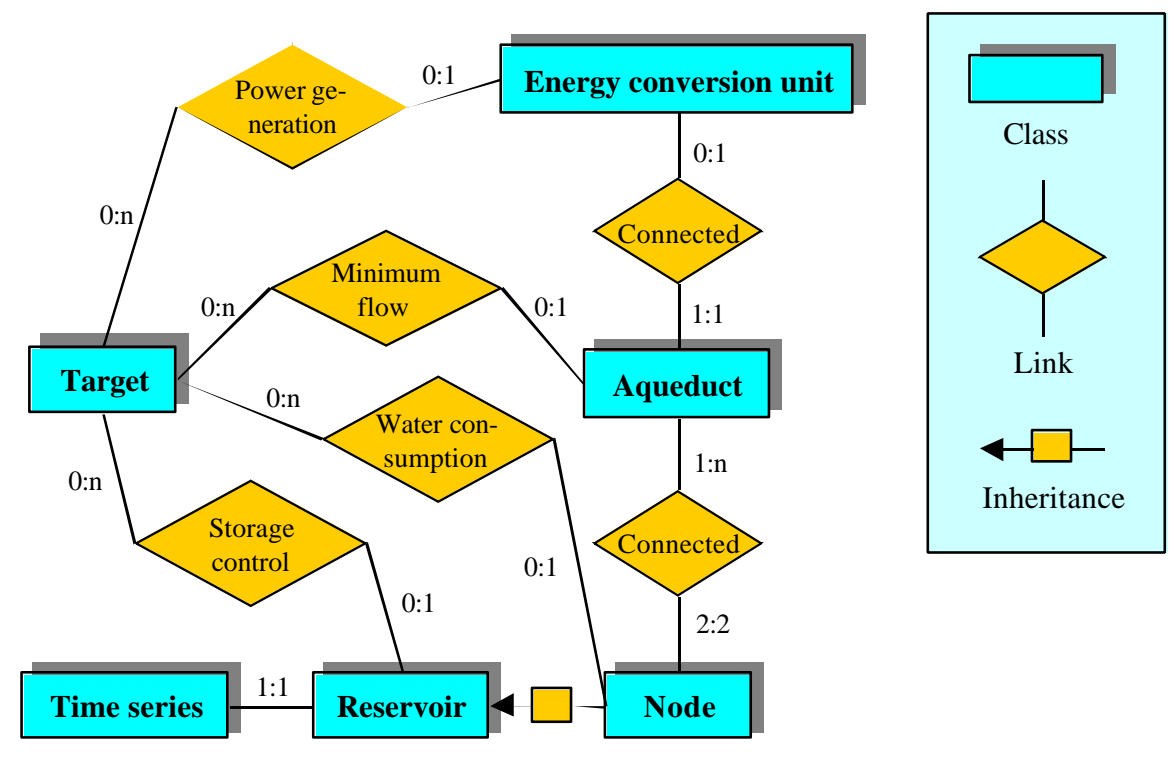

Figure 6 The Entity-Relationship Diagram of Hydronomeas.

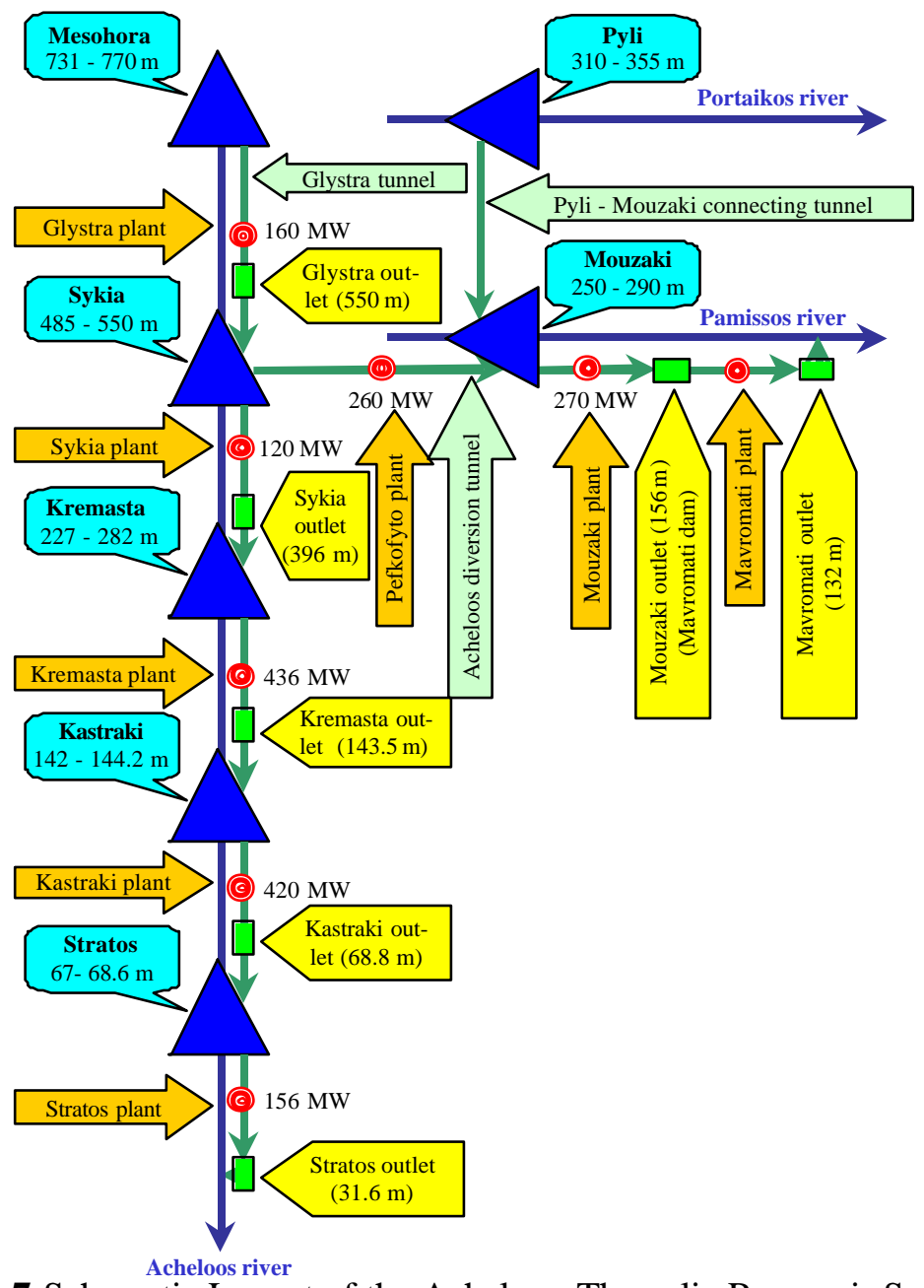

Figure 7 Schematic Layout of the Acheloos-Thessalia Reservoir System. 


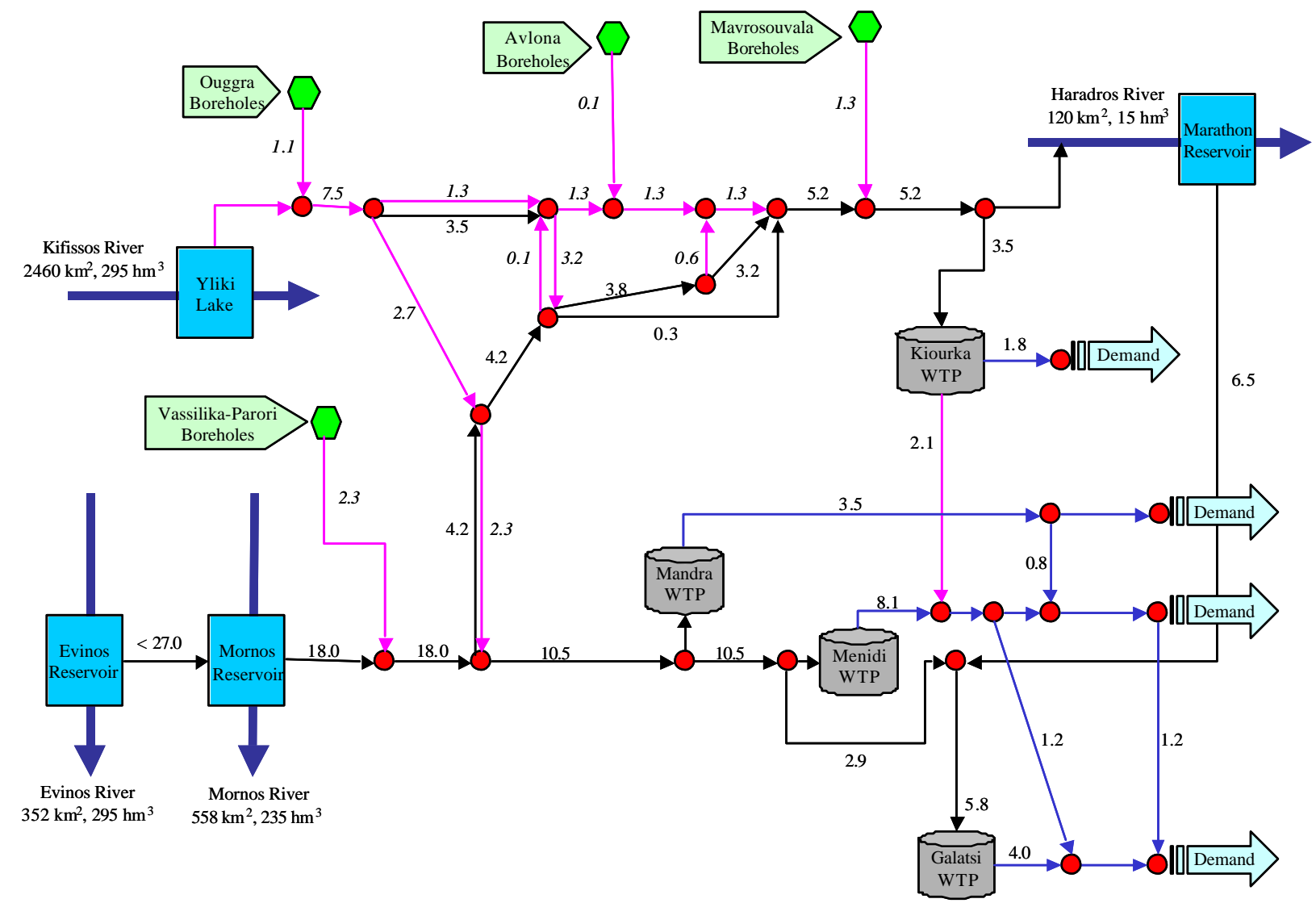

Figure 8 Schematic Layout of the Greater Athens Water Supply Reservoir System.

Note: Characteristic data of the system are annotated; for reservoirs, the watershed area and the mean annual runoff; for aqueducts, the monthly conveyance capacity (in $\mathrm{m}^{3} / \mathrm{s}$ ), with regular letters for gravity flow and with italic letters for pumped flow.
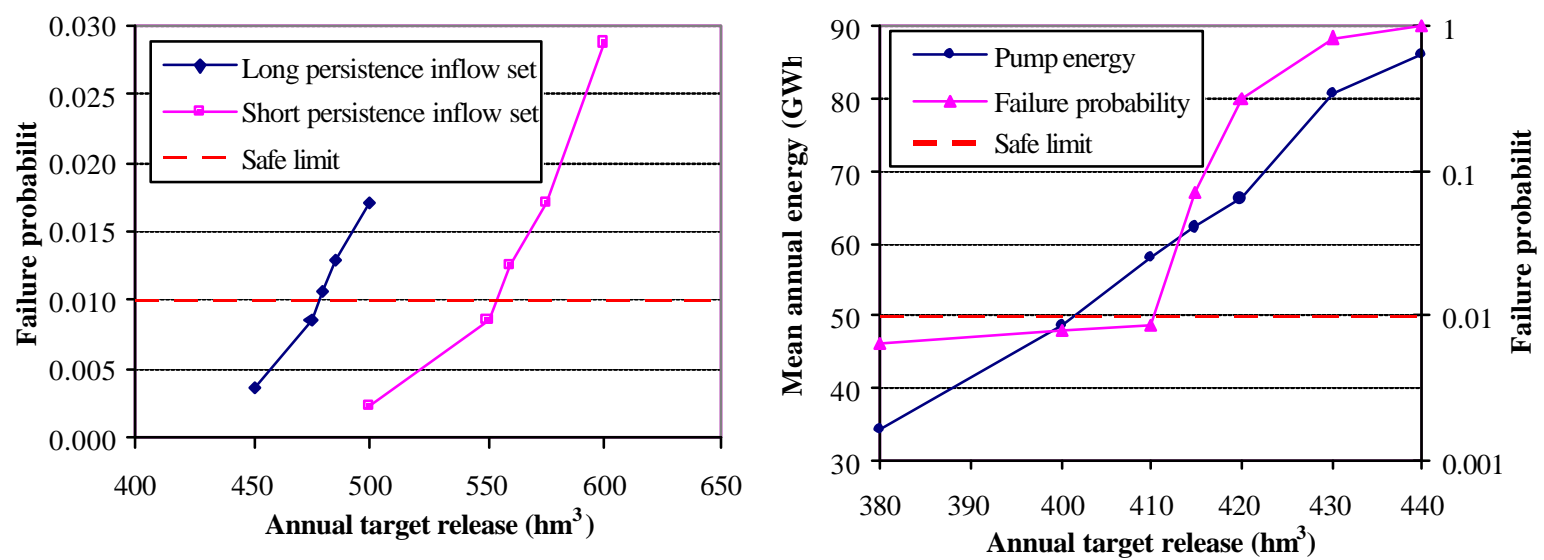

Figure 9 Mean annual release for Athens water supply, according to the scenarios examined.

Note: On the left side is the plot of the theoretical release versus the failure probability, assuming infinite discharge capacity of aqueducts. On the right side is the plot of the real release and the mean annual pump energy versus the failure probability. 
Table 1 Conservation Storage Ranges for Reservoirs of the Acheloos-Thessalia System

\begin{tabular}{|l|c|c|c|c|}
\hline \multirow{2}{*}{ Reservoir } & \multicolumn{2}{|c|}{ Minimum } & \multicolumn{2}{c|}{ Maximum } \\
\cline { 2 - 5 } & Storage $\left(\mathrm{hm}^{5}\right)$ & Level $(\mathrm{m})$ & Storage $\left(\mathrm{hm}^{3}\right)$ & Level $(\mathrm{m})$ \\
\hline Mesohora & 132.8 & 731 & 358.0 & 770 \\
\hline Sykia & 94.0 & 485 & 590.8 & 550 \\
\hline Kremasta & 999.0 & 227 & 4500.0 & 282 \\
\hline Kastraki & 750.0 & 142 & 800.0 & 144 \\
\hline Stratos & 60.0 & 67 & 70.2 & 69 \\
\hline Pyli & 21.7 & 310 & 68.7 & 335 \\
\hline Mouzaki & 54.4 & 250 & 237.2 & 290 \\
\hline
\end{tabular}

Table 2 Hydroelectric Plant Characteristics of the Acheloos-Thessalia System

\begin{tabular}{|l|c|c|}
\hline Power plant & Number of units & Installed capacity (MW) \\
\hline Mesohora & 2 & 160 \\
\hline Sykia & 2 & 120 \\
\hline Kremasta & 4 & 436 \\
\hline Kastraki & 4 & 320 \\
\hline Stratos & 2 & 156 \\
\hline Pefkofyto & 2 & 260 \\
\hline Mouzaki & 2 & 270 \\
\hline
\end{tabular}

Table 3 Summary of Mean Annual Results for the Acheloos-Thessalia System (in GWh)

\begin{tabular}{|l|r|r|r|r|r|}
\hline Scenario & \multicolumn{1}{|c|}{1} & \multicolumn{1}{c|}{$2 \mathrm{a}$} & \multicolumn{1}{c|}{$2 \mathrm{~b}$} & \multicolumn{1}{c|}{3} & \multicolumn{1}{c|}{4} \\
\hline Firm energy & 1167 & 1633 & 1126 & 1249 & 2144 \\
\hline Secondary energy & 839 & 1222 & 1201 & 465 & 1197 \\
\hline Pumping energy & - & - & - & 769 & 578 \\
\hline Total energy & 2006 & 2855 & 2327 & 945 & 2763 \\
\hline
\end{tabular}

Table 4 Reservoir Characteristics of the Greater Athens Water Supply System

\begin{tabular}{|l|c|c|c|c|}
\hline \multirow{2}{*}{ Reservoir } & \multicolumn{2}{|c|}{ Minimum } & \multicolumn{2}{c|}{ Maximum } \\
\cline { 2 - 5 } & Storage $\left(\mathrm{hm}^{3}\right)$ & Level $(\mathrm{m})$ & Storage $\left(\mathrm{hm}^{3}\right)$ & Level $(\mathrm{m})$ \\
\hline Evinos & 27 & 455 & 140 & 500 \\
\hline Mornos & 127 & 382 & 770 & 435 \\
\hline Yliki Lake & 10 & 45 & 587 & 78 \\
\hline Marathon & 7 & 186 & 41 & 223 \\
\hline
\end{tabular}

